\title{
Correction to: Kindergarten and First-Grade Students' Understandings and Representations of Arithmetic Properties
}

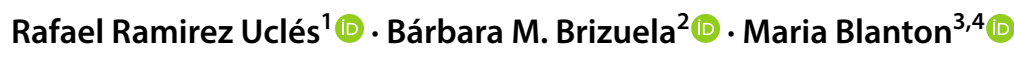 \\ Published online: 10 November 2020 \\ (c) Springer Nature B.V. 2020 \\ Correction to: Early Childhood Education Journal \\ https://doi.org/10.1007/s10643-020-01123-8
}

The original version of this article unfortunately contained a typo in co-author name.

The author name is "Rafael Ramírez Uclés" instead it was published incorrectly as "Rafael Ramírez Úcles".

The original article has been corrected.

Publisher's Note Springer Nature remains neutral with regard to jurisdictional claims in published maps and institutional affiliations.

The original article can be found online at https://doi.org/10.1007/ s10643-020-01123-8.

Rafael Ramirez Uclés

rramirez@ugr.es

Bárbara M. Brizuela

barbara.brizuela@tufts.edu

Maria Blanton

maria_blanton@terc.edu

1 University of Granada, Campus de Cartuja s/n, 18071 Granada, Spain

2 Department of Education, Tufts University, 12 Upper Campus Rd., Paige Hall, Medford, MA 02155, USA

3 TERC, Inc. I Because Math and Science Build Futures, 2067 Massachusetts Avenue, Cambridge, MA 02140, USA

4 Project LEAP

https://www.leap.terc.edu 